Mathématiques et sciences humaines
Mathematics and social sciences

157 | Printemps 2002

Varia

\title{
G. Dowek, "Peut-on croire les sondages ?", Paris, éditions Le Pommier, 2002, $65 \mathrm{p}$
}

G. Dowek, "Peut-on croire les sondages ?", Paris, éditions Le Pommier, 2002, 65 p

\section{Marc Barbut}

\section{(2) OpenEdition}

1 Journals

Édition électronique

URL : http://journals.openedition.org/msh/2957

DOI : $10.4000 / \mathrm{msh} .2957$

ISSN : $1950-6821$

Éditeur

Centre d'analyse et de mathématique sociales de l'EHESS

Édition imprimée

Date de publication : 1 mars 2002

ISSN : 0987-6936

Référence électronique

Marc Barbut, « G. Dowek, "Peut-on croire les sondages ?", Paris, éditions Le Pommier, 2002, 65 p », Mathématiques et sciences humaines [En ligne], 157 | Printemps 2002, mis en ligne le 10 février 2006, consulté le 25 septembre 2020. URL : http://journals.openedition.org/msh/2957 ; DOI : https:// doi.org/10.4000/msh.2957 


\section{BIBLIOGRAPHIE CRITIQUE}

G. DOWEK, Peut-on croire les sondages?, éditions «Le Pommier », Paris, 2002, 65 p.

Les jeunes éditions du Pommier publient en format de poche (et même d'une petite poche) la série «Les petites pommes du savoir» dont l'ouvrage signalé ici est le $n^{\circ} 7$. Chacun des titres de cette série est en forme de point d'interrogation. Exemples : «Pourquoi la mer est-elle bleue ?» $\left(\mathrm{n}^{\circ} 3\right)$, «La radioactivité est-elle réellement dangereuse ?» $\left(\mathrm{n}^{\circ} 8\right)$.

L'opuscule de G. Dowek fournit en un volume réduit (65 pages, format $10 \square$ 16) un exposé très remarquable, tant par sa clarté que par sa brièveté, de l'essentiel de ce que le statisticien a à dire sur le sujet si controversé (et bien d'actualité) des sondages d'opinion.

Je ne saurais donc trop recommander la lecture de ce texte, où ceux qui ont à enseigner la statistique trouveront un modèle de cours pour «non-spécialistes » et même pour « littéraires »; l'auteur a réussi là un tour de force quant à la pédagogie de la statistique.

Je regrette seulement que G. Dowek n'ait abordé que le cas des tirages indépendants (loi binomiale) et n' ait fait aucune allusion aux approximations par la loi de Laplace-Gauss; ni d'ailleurs à la modification des résultats dans le cas de tirages «sans remise » pour le cas, dont il donne un exemple fictif, où la taille de la population sondée n'est pas un «grand nombre». Il aurait également dû, je pense, fournir l'expression $\sqrt{\frac{p q}{n}}$ de l'écart-type pour que le lecteur soit en mesure de calculer luimême une valeur approchée de la «fourchette » dans les sondages dont l'abreuvent les journaux.

Bien sûr, la place exiguë qui lui était impartie a obligé G. Dowek à opérer des choix, et à ne garder que l'essentiel. Mais quelques notes de bas de page auraient suffi pour satisfaire un lecteur qui pourrait se poser des questions au-delà de ce qui est dans le livre : ce seul fait de donner envie d'en savoir plus, montre au demeurant que cet ouvrage constitue une réussite pédagogique.

J'ajoute enfin que le style de G. Dowek est très alerte, ce qui contribue à rendre la lecture de « Peut-on croire les sondages ? » particulièrement attrayante.

En conclusion : lecture fortement recommandée. 